\title{
Evaluation of Minimally Invasive, Ultrasound-guided Synovial Biopsy Techniques by the OMERACT Filter - Determining Validation Requirements
}

\author{
Frances Humby, Stephen Kelly, Serena Bugatti, Antonio Manzo, Andrew Filer, Arti Mahto, \\ Joao Eurico Fonseca, Bernard Lauwerys, Maria-Antonietta D'Agostino, Esperanza Naredo, \\ Rik Lories, Carlomaurizio Montecucco, Paul Peter Tak, Oliver Fitzgerald, Malcolm D. Smith, \\ Douglas J. Veale, Ernest H. Choy, Vibeke Strand, and Costantino Pitzalis
}

ABSTRACT. Objective. Because limited data currently support the clinical utility of peripherally expressed
biomarkers in guiding treatment decisions for patients with rheumatoid arthritis, the search has turned
to the disease tissue. The strategic aim of the Outcome Measures in Rheumatology (OMERACT)
synovitis working group over the years has been to develop novel diagnostic and prognostic synovial
biomarkers. A critical step in this process is to refine and validate minimally invasive, technically
simple, robust techniques to sample synovial tissue, for use both in clinical trials and routine clinical
practice. The objective of the synovitis working group (SWG) at OMERACT 12 (2014) was to
examine whether recently developed ultrasound (US)-guided synovial biopsy techniques could be
validated according to the OMERACT filter for future clinical use recommendation. Methods. The SWG examined whether current data reporting US-guided synovial biopsy of both large and small joints addressed the OMERACT filters of truth, discrimination, and feasibility.

Results. There are currently limited data examining the performance of US-guided synovial biopsy, mainly from observational studies. Thus, it remains critical to evaluate its performance, within the clinical trials context, against the current gold standard of arthroscopic biopsy, with particular reference to: (1) synovial tissue yield, (2) capacity to determine treatment response as measured by a validated synovial biomarker, and (3) tolerability of the procedure.

Conclusion. We summarize the discrete work packages agreed to as requirements to validate US-guided synovial biopsy and therefore lead to a global consensus on the use of synovial biopsy for research and clinical practice. (First Release June 1 2015; J Rheumatol 2016;43:208-13; doi:10.3899/jrheum.141199)

Key Indexing Terms:

$\begin{array}{lll}\text { SYNOVITIS } & \text { BIOPSY RHEUMATOID ARTHRITIS ULTRASOUND }\end{array}$

\footnotetext{
From the Centre for Experimental Medicine and Rheumatology, William Harvey Research Institute at Barts, and the London School of Medicine and Dentistry, Queen Mary University of London, London, UK; Rheumatology and Translational Immunology Research Laboratories (LaRIT), Division of Rheumatology, IRCCS Policlinico San Matteo Foundation/University of Pavia, Pavia, Italy; Rheumatology Research Group, School of Immunity and Infection, College of Medical and Dental Sciences, University of Birmingham, Edgbaston, Birmingham, UK; Rheumatology Research Unit, Instituto de Medicina Molecular, Faculdade de Medicina da Universidade de Lisboa, and Rheumatology Department, Lisbon Academic Medical Centre, Lisbon, Portugal; Institut de Recherche Expérimentale et Clinique, Université Catholique de Louvain and Department of Rheumatology, Cliniques Universitaires Saint-Luc, Brussels, Belgium; Rheumatology Department, Ambroise Paré Hospital, APHP, Université Versailles Saint Quentin en Yvelines, Inserm U987, Boulogne-Billancourt, France; Rheumatology Department, Hospital Universitario Severo Ochoa, Madrid, Spain; Laboratory for Skeletal Development and Joint Disorders, Department of Development and Regeneration, KU Leuven, Leuven, Belgium; University of Cambridge, Cambridge, UK; GlaxoSmithKline Research and Development, Stevenage, UK; School of Medicine and Medical Science, St. Vincent's University Hospital, Dublin, Ireland; Rheumatology Research Unit, Repatriation General Hospital, Daw Park, South Australia; Dublin Academic Medical Centre, The Conway Institute of Biomedical and Biomolecular Research, University College Dublin, Dublin, Ireland; Cardiff Institute of Infection
} 
Cambridge, Cambridge, UK and GlaxoSmithKline Research and Development; O. Fitzgerald, MD, School of Medicine and Medical Science, St. Vincent's University Hospital; M.D. Smith, MD, Rheumatology Research Unit, Repatriation General Hospital; D. Veale, MD, Dublin Academic Medical Centre, The Conway Institute of Biomedical and Biomolecular Research, University College Dublin, and St. Vincent's University Hospital; E.H. Choy, FRCP, Cardiff Institute of Infection and Immunity, Cardiff Regional Experimental Arthritis Treatment and Evaluation Centre; V. Strand, MD, Division of Immunology/Rheumatology, Stanford University School of Medicine; C. Pitzalis, FRCP Centre for Experimental Medicine and Rheumatology, William Harvey Research Institute at Barts and the London School of Medicine and Dentistry, Queen Mary University of London.

Address correspondence to Prof. C. Pitzalis, Centre for Experimental Medicine and Rheumatology, William Harvey Research Institute, John Vane Science Centre, Queen Mary University of London, London, EC1M 6BQ,UK.E-mail: c.pitzalis@qmul.ac.uk

In the past 2 decades the critical association between ongoing synovitis and structural damage in patients with rheumatoid arthritis (RA) has been recognized and has contributed to a paradigm shift in treatment with a sustained treat-to-target approach, now accepted as "gold standard" therapy ${ }^{1}$. In part fueled by the development of novel biologic agents, this approach has generated significant longterm improvements ${ }^{2}$. However, our ability to induce sustained remission and/or cure on an individual level remains limited, with insufficient information to guide selection of therapy based on prognosis and/or predicted response to treatment ${ }^{3}$. Because limited data currently support the clinical utility of peripherally expressed biomarkers $4,5,6,7$, focus has turned to the use of synovial tissue biomarkers $8,9,10,11,12,13$. This is consistent with practice in other medical specialties such as oncology, where examination of pathobiological specimens from disease tissue have demonstrated prognostic value and are now integrated into standard care. In RA, however, synovial biopsy is not currently considered as a standard intervention in either routine care or in randomized controlled trials (RCT) for a variety of reasons ${ }^{14}$. Thus, the strategic aims and objectives of the Outcome Measures in Rheumatology (OMERACT) synovitis working group (SWG) are to develop a minimally invasive, simple, well-tolerated, and robust technique to sample synovial tissue from most patients/joints to use in turn to develop novel diagnostic/prognostic biomarkers ${ }^{15,16}$.

The objective of the SWG at OMERACT 12 (2014) was, therefore, to examine whether recently developed ultrasound (US)-guided synovial biopsy techniques could be validated and recommended for future use to monitor therapeutic responses in RCT and/or for patient stratification.

\section{Current Status on Synovial Tissue Acquisition}

Acquisition of synovial tissue using an arthroscopic approach in RCT is currently recommended ${ }^{14}$ based on: (1) extensive data confirming the safety and tolerability of the procedure $^{17,18,19}$, (2) its ability to sample synovial tissue from multiple sites within the joint, and (3) the means to sample joints with minimal synovitis ${ }^{20}$. However, outside of highly specialized centers, routine arthroscopic sampling of synovial tissue has not been widely adopted. This is due to a number of factors: technical training required for the procedure ${ }^{19}$, economic cost of the required equipment and capacity/infrastructure $^{19,21}$, and the general acceptability of a relatively invasive technique to patients and/or their rheumatologists. Importantly, based on the recognition that small joint involvement is often prominent in early arthritis ${ }^{22}$, and large joint involvement is associated with more severe and established disease ${ }^{23}$, there is increasing interest in acquiring synovial tissue from small synovial joints ${ }^{24,25}$ to understand the early stages of disease pathogenesis by clearly distinguishing mechanistic pathways, as well as to ensure the recruitment of representative RA cohorts into RCT. However, even with small-bore arthroscopy ${ }^{26}$, the limitations of the procedure remain. Unless less-invasive techniques are validated, synovial biopsy is unlikely to be widely adopted.

Thus techniques using US to direct synovial tissue sampling are attractive: they are minimally invasive, applicable to both large and small joints, relatively inexpensive to perform, and technically simple. Two principal techniques for performance have been described: a portal and forceps (P\&F) approach ${ }^{27}$ and more recently, adaptation using a quick core needle ${ }^{28}$. Both techniques use US to locate a suitable area of synovial tissue to biopsy. The P\&F approach uses a 14-16G introducer, guide wire, and coaxial sheath. The coaxial sheath remains in situ during the procedure and facilitates repeated introduction of biopsy forceps to the joint. Conversely, the US-needle biopsy (NB) technique uses either a 14- or 16-G needle repeatedly entered into the joint without requiring insertion of a relatively larger coaxial sheath (Figure 1).

Although US-guided biopsies may offer distinct advantages over arthroscopic sampling (Table 1), this approach cannot be recommended for use within RCT until it has been shown to fulfill the OMERACT filter of truth, discrimination, and feasibility.

\section{MATERIALS AND METHODS}

The SWG met at OMERACT 12 (2014) to discuss currently available data examining the performance of US-guided synovial biopsy against the OMERACT filters of truth, discrimination, and feasibility and to define future discrete work packages to validate the technique for use in clinical trials.

\section{RESULTS OMERACT Filter "Truth"}

Synovial biopsy of large joints. US-guided synovial biopsies of large joints using a $\mathrm{P} \& \mathrm{~F}^{29,30}$ and NB approaches have been reported with success rates of $89-93 \%{ }^{28,30}$ for histopathological analyses and extraction of good-quality RNA from all samples reported. To overcome the heterogeneity of synovial tissue sampling in large joints, current OMERACT recommendations include acquisition from separate sites of at least 6 biopsies for histopathological and gene expression analysis, respectively ${ }^{14}$. Such a standard has not been evaluated for

$$
\text { Personal non-commercial use only. The Journal of Rheumatology Copyright (c) 2016. All rights reserved. }
$$



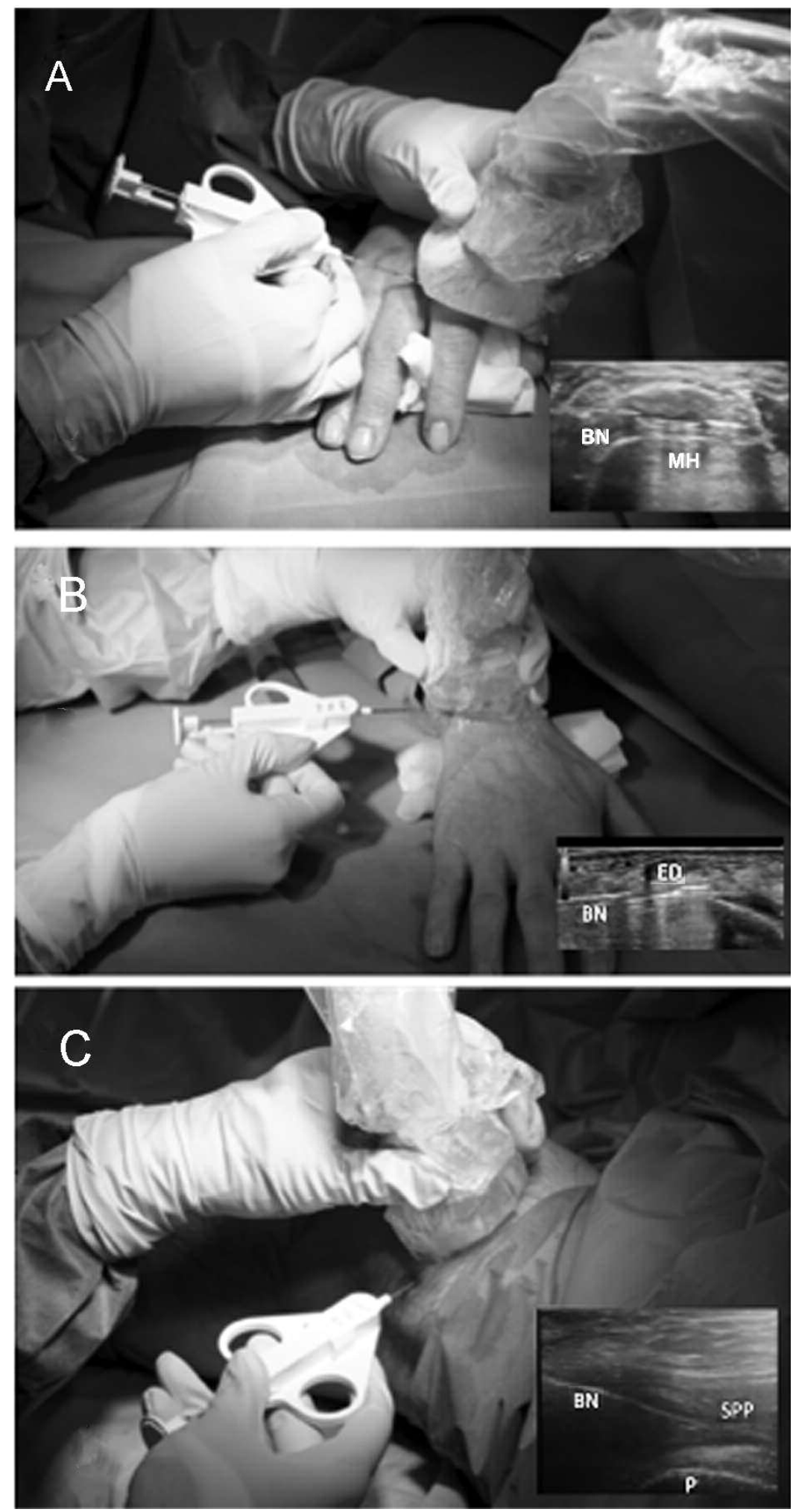

Figure 1. US-guided synovial biopsy. A. US-guided needle biopsy (NB) of the metacarpophalangeal (MCP) joint; inset shows transverse US image of biopsy needle (BN) insertion into MCP joint space (MH, metacarpal head). B. US-guided NB of wrist joint. Inset illustrates transverse image of biopsy needle insertion into wrist joint under extensor digitorum (ED) tendon. C. US-guided synovial biopsy of knee joint. Inset illustrates transverse image of biopsy needle insertion into suprapatellar pouch (SPP; P: patellar). US: ultrasound. 
Table 1. Relative merits of techniques currently used in clinical trials to sample synovial tissue.

\begin{tabular}{|c|c|c|c|c|c|c|}
\hline & \multicolumn{2}{|c|}{ Arthroscopy } & \multicolumn{2}{|c|}{$\begin{array}{l}\text { US-guided P\&F } \\
\text { Joint Size }\end{array}$} & \multicolumn{2}{|c|}{ US-guided NB } \\
\hline & Large & Small & Large & Small & Large & Small \\
\hline Validation & +++ & + & + & ++ & + & + \\
\hline Technically simple & + & + & ++ & ++ & +++ & +++ \\
\hline Patient acceptability** & +++ & $*$ & $*$ & $*$ & +++ & +++ \\
\hline Suitable for serial biopsies & +++ & +++ & $*$ & $*$ & ++ & ++ \\
\hline
\end{tabular}

*No data available; **No data available that directly compare techniques. P\&F: portal and forceps; NB: needle biopsy; US: ultrasound.

either US-guided technique. Given the distinct differences in biopsy tools (i.e., forceps vs needle), it is also critical to evaluate the yield of synovial tissue (histopathological and RNA) between each technique and to compare these data against the current gold standard of arthroscopy.

Small joint biopsy. Data support the use of US-guided biopsy of small joints using both the $\mathrm{P} \& \mathrm{~F}^{27}$ and NB techniques ${ }^{28}$. However, in comparison with extensive validation data available for large joint biopsies, limited data are available for small joints. One report indicates that US-P\&F biopsy of small joints ${ }^{28}$ provides sufficient tissue for reliable histopathological assessment; however, this validation exercise was restricted to defining the biopsy area (rather than biopsy number) and therefore is difficult to extrapolate to routine practice. Further, given the interest in sampling small joints with minimal synovitis, particularly following effective treatment, it is also important to recognize that serial sampling using US-NB has been reported to be feasible ${ }^{28}$ whereas US-P\&F approach has not, primarily because of the challenge of inserting a larger coaxial sheath into minimally inflamed joints. As with large joints, currently there has been no systematic examination of overall yield of synovial tissue sampled using US-NB from small joints.

Therefore, key steps to be addressed before US-guided needle biopsy of small joints can be recommended in RA include: (1) to define the minimum number of biopsies required per procedure to ensure accurate histopathological assessment and adequate RNA yield; and (2) to systematically address whether US-guided biopsy reaches these defined standards for small joints.

\section{OMERACT Filter "Discrimination"}

The number of sublining CD68+ macrophages remains the only validated synovial biomarker recommended by OMERACT, with data to indicate that it varies according to clinical response $\mathrm{e}^{31}$ and is not modulated by ineffective therapy ${ }^{32}$. Its performance, using arthroscopic biopsies within the setting of multicenter RCT, has been reported ${ }^{33,34}$. However, whether the sublining macrophage number obtained from synovial tissue using US-guided biopsies discriminates between clinical disease states and active therapy has not been reported, and examining this within the context of a clinical trial remains an important validation step.

\section{OMERACT Filter "Feasibility"}

When considering the feasibility for broad adoption of US-guided biopsy into RCT and routine clinical care, a crucial step will be determination of its acceptability to patients. Although there are data to support the safety of both US-NB ${ }^{28}$ and US-P\&F ${ }^{30}$ and acceptable tolerability of US-NB in a small cohort ${ }^{28}$, both will require further evaluation, including through the application of patient questionnaires within large RCT. Further, examining a "learning curve" for clinicians undergoing training in US-guided

Table 2. Summary of planned validation exercises to evaluate US-guided synovial biopsy versus arthroscopy according to the OMERACT filter.

\begin{tabular}{llcc}
\hline OMERACT Filter & Standard to Assess Per Procedure & Procedures to Evaluate & Joints \\
\hline Truth & $\begin{array}{l}\text { Histopathological quality } \\
\text { RNA yield }\end{array}$ & $\begin{array}{l}\text { US-NB, US-P\&F } \\
\text { US-NB, US-P\&F }\end{array}$ & $\begin{array}{l}\text { Large and small } \\
\text { Large and small }\end{array}$ \\
& $\begin{array}{l}\text { Sublining macrophage number versus } \\
\text { clinical response }\end{array}$ & US-NB, US-P\&F & Large and small \\
Feasibility & $\begin{array}{l}\text { Patient acceptability } \\
\text { Evaluation of performance in a } \\
\text { multicenter clinical trial } \\
\text { Defining learning curve for new operators }\end{array}$ & US-NB, US-P\&F & Large and small \\
& US-NB, US-P\&F & Large and small \\
& & Large and small \\
\hline
\end{tabular}

US: ultrasound; P\&F: portal and forceps; NB: needle biopsy. 
synovial biopsy by defining numbers of observed/supervised procedures would be of critical importance to permit the development of robust training requirements for trainees.

Applying US-guided synovial biopsy to RCT. Evidence from observational studies already indicate that synovial biomarkers can predict responses to biologic therapy in $\mathrm{RA}^{9,35,36}$, and this hypothesis is currently being examined in 2 UK-wide RCT funded by: (1) the R4RA (National Institute for Health Research: Response, Relapse, Resistance to Rituximab study); and (2) STRAP (Stratification of Biologic Therapies for Rheumatoid Arthritis by Pathobiology study), jointly funded by the Medical Research Council and Arthritis Research UK. Such trials are critical to thoroughly examine whether synovial biopsy offers clinical utility in the unbiased environment of a RCT. This would address 1 of the core aims of the SWG, because US-guided biopsy is incorporated into both of the above RCT protocols, while the comparison of sampling methods with arthroscopy using descriptive, correlation, and reliability statistics will provide a unique platform to examine the performance of the procedures in the context of multicenter RCT. Critical research questions posed within the studies will also offer the opportunity to perform a resource use/economic impact assessment, as a core domain included within the recently revised OMERACT Filter 2.0 framework ${ }^{37}$.

The principal research agenda set by the SWG at OMERACT 12 is to deliver the discrete work packages that will lead to a global consensus on the use of synovial biopsy for research and clinical practice. Further, a systematic literature review of currently available synovial biopsy techniques in the context of clinical trials will be performed. The discrete work packages are summarized in Table 2 and focus on validation of a minimally invasive synovial biopsy technique for both small and large joints in RA - critical to facilitate the group's overarching aim to identify synovial biomarkers for treatment response, diagnosis, and/or prognosis.

\section{REFERENCES}

1. Schoels M, Knevel R, Aletaha D, Bijlsma JW, Breedveld FC, Boumpas DT, et al. Evidence for treating rheumatoid arthritis to target: results of a systematic literature search. Ann Rheum Dis 2010;69:638-43.

2. Breedveld FC, Combe B. Understanding emerging treatment paradigms in rheumatoid arthritis. Arthritis Res Ther 2011;13:S3.

3. Choy EH, Kavanaugh AF, Jones SA. The problem of choice: current biologic agents and future prospects in RA. Nat Rev Rheumatol 2013;9:154-63.

4. Sekiguchi N, Kawauchi S, Furuya T, Inaba N, Matsuda K, Ando S, et al. Messenger ribonucleic acid expression profile in peripheral blood cells from RA patients following treatment with an anti-TNF-alpha monoclonal antibody, infliximab. Rheumatology 2008;47:780-8.

5. Lequerre T, Gauthier-Jauneau AC, Bansard C, Derambure C, Hiron $\mathrm{M}$, Vittecoq $\mathrm{O}$, et al. Gene profiling in white blood cells predicts infliximab responsiveness in rheumatoid arthritis. Arthritis Res Ther 2006;8:R105.
6. Koczan D, Drynda S, Hecker M, Drynda A, Guthke R, Kekow J, et al. Molecular discrimination of responders and nonresponders to anti-TNF alpha therapy in rheumatoid arthritis by etanercept. Arthritis Res Ther 2008;10:R50.

7. Marotte H, Maslinski W, Miossec P. Circulating tumour necrosis factor-alpha bioactivity in rheumatoid arthritis patients treated with infliximab: link to clinical response. Arthritis Res Ther 2005;7:R149-55.

8. Lindberg J, Wijbrandts CA, van Baarsen LG, Nader G, Klareskog $\mathrm{L}$, Catrina A, et al. The gene expression profile in the synovium as a predictor of the clinical response to infliximab treatment in rheumatoid arthritis. PloS One 2010;5:e11310.

9. Dennis G, Holweg C, Kummerfeld S, Choy D, Setiadi F, Hackney $\mathrm{J}$, et al. Synovial phenotypes in rheumatoid arthritis correlate with response to biologic therapeutics. Arthritis Res Ther 2014;16:R90.

10. Pitzalis C, Kelly S, Humby F. New learnings on the pathophysiology of RA from synovial biopsies. Current Opin Rheumatol 2013;25:334-44.

11. Pitzalis C, Jones GW, Bombardieri M, Jones SA. Ectopic lymphoid-like structures in infection, cancer and autoimmunity. Nat Rev Immunol 2014;14:447-62.

12. Wechalekar M, Smith M. Utility of arthroscopic guided synovial biopsy in understanding synovial tissue pathology in health and disease states. World J Orthop 2014;5:1-8.

13. Wijbrandts CA, Dijkgraaf MG, Kraan MC, Vinkenoog M, Smeets TJ, Dinant $\mathrm{H}$, et al. The clinical response to infliximab in rheumatoid arthritis is in part dependent on pretreatment tumour necrosis factor alpha expression in the synovium. Ann Rheum Dis 2008;67:1139-44.

14. van de Sande MG, Gerlag DM, Lodde BM, van Baarsen LG, Alivernini S, Codullo V, et al. Evaluating antirheumatic treatments using synovial biopsy: a recommendation for standardisation to be used in clinical trials. Ann Rheum Dis 2011;70:423-7.

15. Bresnihan B, Baeten D, Firestein GS, Fitzgerald OM, Gerlag DM, Haringman JJ, et al. Synovial tissue analysis in clinical trials. J Rheumatol 2005;32:2481-4.

16. de Hair MJ, Harty LC, Gerlag DM, Pitzalis C, Veale DJ, Tak PP. Synovial tissue analysis for the discovery of diagnostic and prognostic biomarkers in patients with early arthritis. J Rheumatol 2011;38:2068-72.

17. Gerlag D, Tak PP. Synovial biopsy. Best Prac Res Clin Rheumatol 2005;19:387-400

18. Baeten D, Van den Bosch F, Elewaut D, Stuer A, Veys EM, De Keyser F. Needle arthroscopy of the knee with synovial biopsy sampling: technical experience in 150 patients. Clin Rheumatol 1999;18:434-41.

19. Kane D, Veale DJ, FitzGerald O, Reece R. Survey of arthroscopy performed by rheumatologists. Rheumatology 2002;41:210-5.

20. van de Sande MG, de Hair MJ, van der Leij C, Klarenbeek PL, Bos WH, Smith MD, et al. Different stages of rheumatoid arthritis: features of the synovium in the preclinical phase. Ann Rheum Dis 2011;70:772-7.

21. Smith MD, Baeten D, Ulfgren AK, McInnes IB, Fitzgerald O, Bresnihan B, et al. Standardisation of synovial tissue infiltrate analysis: how far have we come? How much further do we need to go? Ann Rheum Dis 2006;65:93-100.

22. van Steenbergen HW, van Nies JA, Huizinga TW, Bloem JL, Reijnierse M, van der Helm-van Mil AH. Characterising arthralgia in the preclinical phase of rheumatoid arthritis using MRI. Ann Rheum Dis 2014 April 9 (E-pub ahead of print).

23. Linn-Rasker SP, van der Helm-van Mil AH, Breedveld FC, Huizinga TW. Arthritis of the large joints - in particular, the knee - at first presentation is predictive for a high level of radiological destruction of the small joints in rheumatoid arthritis. Ann Rheum Dis 2007;66:646-50. 
24. Veale DJ. The role of arthroscopy in early arthritis. Clin Exp Rheumatol 1999;17:37-8.

25. Kraan MC, Reece RJ, Smeets TJ, Veale DJ, Emery P, Tak PP. Comparison of synovial tissues from the knee joints and the small joints of rheumatoid arthritis patients: Implications for pathogenesis and evaluation of treatment. Arthritis Rheumatol 2002;46:2034-8.

26. Andersen M, Boesen M, Ellegaard K, Christensen R, Soderstrom $\mathrm{K}$, Soe N, et al. Synovial explant inflammatory mediator production corresponds to rheumatoid arthritis imaging hallmarks: a cross sectional study. Arthritis Res Ther 2014;16:R107.

27. Scire CA, Epis O, Codullo V, Humby F, Morbini P, Manzo A, et al. Immunohistological assessment of the synovial tissue in small joints in rheumatoid arthritis: validation of a minimally invasive ultrasound-guided synovial biopsy procedure. Arthritis Res Ther 2007;9:R101.

28. Kelly S, Humby F, Filer A, Ng N, Di Cicco M, Hands RE, et al. Ultrasound-guided synovial biopsy: a safe, well-tolerated and reliable technique for obtaining high-quality synovial tissue from both large and small joints in early arthritis patients. Ann Rheum Dis 2015;74:611-7.

29. Kaiser MJ, Hauzeur JP, Blacher S, Foidart JM, Deprez M, Rossknecht A, et al. Contrast-enhanced coded phase-inversion harmonic sonography of knee synovitis correlates with histological vessel density: 2 automated digital quantifications. J Rheumatol 2009;36:1391-400.

30. Koski JM, Helle M. Ultrasound guided synovial biopsy using portal and forceps. Ann Rheum Dis 2005;6:926-9.

31. Haringman JJ, Gerlag DM, Zwinderman AH, Smeets TJ, Kraan MC, Baeten D, et al. Synovial tissue macrophages: a sensitive biomarker for response to treatment in patients with rheumatoid arthritis. Ann Rheum Dis 2005;64:834-8.

32. Wijbrandts CA, Vergunst CE, Haringman JJ, Gerlag DM, Smeets TJ, Tak PP. Absence of changes in the number of synovial sublining macrophages after ineffective treatment for rheumatoid arthritis: implications for use of synovial sublining macrophages as a biomarker. Arthritis Rheum 2007;56:3869-71.

33. Bresnihan B, Pontifex E, Thurlings RM, Vinkenoog M, El-Gabalawy H, Fearon U, et al. Synovial tissue sublining CD68 expression is a biomarker of therapeutic response in rheumatoid arthritis clinical trials: consistency across centers. J Rheumatol 2009;36:1800-2.

34. Bresnihan B, Gerlag DM, Rooney T, Smeets TJ, Wijbrandts CA, Boyle D, et al. Synovial macrophages as a biomarker of response to therapeutic intervention in rheumatoid arthritis: standardization and consistency across centers. J Rheumatol 2007;34:620-2.

35. Rooney T, Roux-Lombard P, Veale DJ, FitzGerald O, Dayer JM, Bresnihan B. Synovial tissue and serum biomarkers of disease activity, therapeutic response and radiographic progression: analysis of a proof-of-concept randomised clinical trial of cytokine blockade. Ann Rheum Dis 2010;69:706-14.

36. Ducreux J, Durez P, Galant C, Nzeusseu Toukap A, Van den Eynde B, Houssiau FA, et al. Global molecular effects of tocilizumab therapy in rheumatoid arthritis synovium. Arthritis Rheumatol 2014;66:15-23.

37. Boers M, Kirwan JR, Wells G, Beaton D, Gossec L, d'Agostino MA, et al. Developing core outcome measurement sets for clinical trials: OMERACT Filter 2.0. J Clin Epidemiol 2014;67:745-53. 